\title{
Erratum to: $N$-Methyl-2-pyridone-5-carboxamide is 1-methylnicotinamide metabolite of low cyclooxygenase-dependent vasodilating activity
}

\author{
Tomasz Przygodzki • Bartlomiej Grobelski • \\ Piotr Kazmierczak • Cezary Watala
}

Published online: 15 February 2012

(C) University of Navarra 2012

\section{Erratum to: J Physiol Biochem \\ DOI 10.1007/s13105-012-0144-4}

Unfortunately, the legend of figure 2 of this manuscript contained two errors, where $\mu$ symbols were replaced by a . The correct legend to figure 2 should be:

Fig. 2 Effect of selective COX-2 inhibitor, NS-398, and indomethacin on 6-keto-PGF $1 \alpha$ and PGE2 secretion. NS-398 and indomethacin used at the concentrations of $25 \mu \mathrm{mol} / 1$ and $50 \mu \mathrm{mol} / 1$, respectively. Data presented as median and interquartile range, min-max ranges marked as whiskers $(n=4$, $* * \mathrm{p}<0.01, * * * \mathrm{p}<0.001)$

The online version of the original article can be found at http://dx. doi.org/10.1007/s13105-012-0144-4.

T. Przygodzki $(\bowtie) \cdot$ B. Grobelski $\cdot$ P. Kazmierczak

C. Watala

Chair of Laboratory Diagnostics,

Department of Haemostasis and Haemostatic Disorders,

University Clinical Hospital No 2,

Medical University of Lodz,

Lodz, Poland

e-mail: tomasz.przygodzki@umed.lodz.pl

P. Kazmierczak

Postgraduate School of Molecular Medicine,

Medical University of Warsaw,

Warsaw, Poland 